\title{
BMJ Open A cross-sectional study measuring vanadium and chromium levels in paediatric patients with CKD
}

\author{
Guido Filler, ${ }^{1,2,3,4}$ Marta Kobrzynski, ${ }^{1,2}$ Hargun Kaur Sidhu, ${ }^{1}$ Vladimir Belostotsky, ${ }^{5}$ \\ Shih-Han S Huang, ${ }^{1,2,3}$ Chris Mclntyre, ${ }^{1,2,3}$ Liju Yang $^{4}$
}

To cite: Filler G, Kobrzynski M, Sidhu HK, et al. A crosssectional study measuring vanadium and chromium levels in paediatric patients with CKD. BMJ Open 2017;0:e014821. doi:10.1136/ bmjopen-2016-014821

- Prepublication history and additional material are available. To view please visit the journal (http://dx.doi.org/10.1136/ bmjopen-2016-014821).

Received 20 0ctober 2016 Revised 8 January 2017 Accepted 1 February 2017

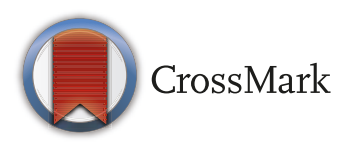

${ }^{1}$ Department of Paediatrics, Division of Paediatric Nephrology, Children's Hospital, London, Ontario, Canada

${ }^{2}$ Lilibeth Caberto Kidney Clinical Research Unit, London Health Sciences Centre, London, Ontario, Canada

${ }^{3}$ Department of Medicine,

Division of Nephrology, Schulich School of Medicine and Dentistry, University of Western Ontario, London, Ontario, Canada

${ }^{4}$ Department of Pathology and Laboratory Medicine, Schulich School of Medicine and Dentistry, University of Western Ontario, London, Ontario, Canada

${ }^{5}$ Department of Paediatrics, Division of Paediatric

Nephrology, McMaster

Children's Hospital, Hamilton, Ontario, Canada

Correspondence to

Dr Guido Filler;

guido.filler@lhsc.on.ca

\section{ABSTRACT}

Objectives Although many secondary effects of high levels of vanadium (V) and chromium (Cr) overlap with symptoms seen in paediatric patients with chronic kidney disease (CKD), their plasma $\mathrm{V}$ and $\mathrm{Cr}$ levels are understudied.

Design Ancillary cross-sectional study to a prospective, longitudinal, randomised controlled trial.

Setting Children's Hospital of Western Ontario, London Health Sciences Centre, London, Ontario, Canada.

Participants 36 children and adolescents $4-18$ years of age with CKD.

Interventions 1-6 trace element measurements per patient. Cystatin C (CysC) estimated glomerular filtration rate (eGFR) was calculated using the Filler formula. Plasma $\mathrm{V}$ and $\mathrm{Cr}$ levels were measured using high-resolution sector field inductively coupled mass spectrometry. Anthropomorphic data and blood parameters were collected from our electronic chart programme. Water $\mathrm{Cr}$ and $\mathrm{V}$ data were obtained from the Ontario Water (Stream) Quality Monitoring Network.

Primary and secondary outcome measures Primary outcomes: plasma $\mathrm{Cr}$ and $\mathrm{V}$. Secondary outcomes: age, season, CysC, CysC eGFR, and $\mathrm{Cr}$ and $\mathrm{V}$ levels in environmental water.

Results The median (IQR) eGFR was $51 \mathrm{~mL} / \mathrm{min} / 1.73 \mathrm{~m}^{2}$ $(35,75)$. The median V level was $0.12 \mu \mathrm{g} / \mathrm{L}(0.09,0.18)$, which was significantly greater than the 97.5 th percentile of the reference interval of $0.088 \mu \mathrm{g} / \mathrm{L} ; 32$ patients had at least one set of $\mathrm{V}$ levels above the published reference interval. The median $\mathrm{Cr}$ level was $0.43 \mu \mathrm{g} / \mathrm{L}(0.36,0.54)$, which was also significantly greater than the established reference interval; 34 had at least one set of $\mathrm{Cr}$ levels above the published reference interval. $\mathrm{V}$ and $\mathrm{Cr}$ levels were moderately correlated. Only some patients had high environmental exposure.

Conclusions Our study suggests that paediatric patients with CKD have elevated plasma levels of $\mathrm{V}$ and $\mathrm{Cr}$. This may be the result of both environmental exposure and a low eGFR. It may be necessary to monitor $\mathrm{V}$ and $\mathrm{Cr}$ levels in patients with an eGFR $<30 \mathrm{~mL} / \mathrm{min} / 1.73 \mathrm{~m}^{2}$.

Trial registration number NCT02126293; HC\#172241.

\section{INTRODUCTION}

Vanadium (V, atomic number 23) and chromium (Cr, atomic number 24) are located beside each other on the periodic table and

\section{Strengths and limitations of this study}

This is the first study to examine vanadium (V) and chromium $(\mathrm{Cr})$ in children with chronic kidney disease (CKD).

- Our study has a strong cross-sectional design in combination with longitudinal data and a reasonable number of patients for a paediatric study. The instruments used to measure the trace elements are highly precise.

- Our study links publicly available data measuring trace elements in drinking water with detailed descriptions of patients to differentiate environmental and CKD-related accumulation of $\mathrm{V}$ and $\mathrm{Cr}$.

- More subjects would have lead to more precise data, and our patient cohort has a bias towards milder CKD stages. We did not control for fluid or food intake.

- There are no detailed studies on the age dependency of paediatric $\mathrm{V}$ and $\mathrm{Cr}$ concentrations.

share many points of similarity. Both are predominantly excreted by the kidneys, ${ }^{12}$ are associated with normal human health and with the pathogenesis of several diseases (ie, essential and toxic) ${ }^{3-6}$ and occur naturally in our surrounding environment. ${ }^{78}$ Metallic $\mathrm{V}$ and $\mathrm{Cr}$ do not occur in nature and are instead found as compounds in different valence states. ${ }^{8-10}$ Humans can be exposed to $\mathrm{V}$ and Cr through the air, but the majority of contact stems from food and water. ${ }^{7811}$ They are usually present in low, harmless concentrations in various foods (particularly seafood for $\mathrm{V}) .{ }^{1}$ Some nutritional supplements and vitamins also contain $\mathrm{V}$, whose levels can exceed healthy levels. ${ }^{411}$

The principal pentavalent form of $\mathrm{V}$ can easily enter a cell via phosphate and sulfate ion channels, rendering this version of $\mathrm{V}$ very toxic. ${ }^{12} \mathrm{~V}$ also interferes with phosphate-containing enzymes ${ }^{34}$ and can activate several genes and participate in the inflammatory response. The highest initial concentrations of $\mathrm{V}$ are found in the kidneys, liver and 
lungs, and in the long-term it is stored in the bones and muscles. ${ }^{1314}$ The effects of $\mathrm{V}$ on human health are largely dependent on the type of compound, ${ }^{11}$ dose, duration and route of exposure. ${ }^{3411}$ The common hexavalent form of $\mathrm{Cr}$ easily enters cells through facilitated uptake, which is more efficient than the simple diffusion used to take up the trivalent form. Free radicals are created in cells when $\mathrm{Cr}(\mathrm{VI})$ is reduced to $\mathrm{Cr}(\mathrm{III}) .{ }^{8}$ It is distributed to and accumulated by the erythrocyte and the highest concentrations of $\mathrm{Cr}$ are found in the kidneys and liver. The absorption fraction of ingested $\mathrm{Cr}$ is higher when dietary intakes are lower. The major route of elimination of absorbed $\mathrm{Cr}$ is through the urine, with unabsorbed $\mathrm{Cr}$ recovered in the faeces, ${ }^{2}$ while $\mathrm{V}$ is also mostly excreted through the urine, with some excretion in the faeces. ${ }^{15}$

$\mathrm{V}$ has many systemic effects, including gastrointestinal, respiratory, haematological, immunological and cardiovascular effects. ${ }^{1} 71617$ The International Agency for Research on Cancer (IARC) has classified V pentoxide as 'possibly carcinogenic'. Other data also suggest the potential of $\mathrm{V}$ to induce developmental effects in humans. It is unknown whether children are affected by V-containing compounds in the same ways as adults. ${ }^{11}$

The IARC has classified $\mathrm{Cr}$ as carcinogenic. Inhalation has been shown to cause lung cancer in humans, and exposure has been shown to cause tumours in the stomach, intestinal tract and lungs in animals. ${ }^{8}$ Depending on the route of exposure, trivalent and hexavalent $\mathrm{Cr}$ are also associated with gastrointestinal, immunological, haematological (including anaemia), reproductive, developmental and other serious effects. Hexavalent $\mathrm{Cr}$ is more toxic than its trivalent form, but trace element measurements rarely differentiate between the two.

The dangers $\mathrm{V}$ and particularly Cr pose to our health are made clear when the serious systemic effects associated with either acute or chronic exposure to either element in humans are explored in greater depth.

Acute oral exposure to $\mathrm{V}$ can cause mild gastrointestinal irritation, such as stomach cramps, mild diarrhoea and nausea. ${ }^{7}$ Although there are no studies examining the effect of chronic oral exposure to $\mathrm{V}$ on human health, chronic exposure to $\mathrm{V}$ through inhalation may cause neurocognitive deficits and may impair neurobehavioural abilities, symptoms that are regularly seen in paediatric patients with chronic kidney disease (CKD) ${ }^{18}$ Chronic exposure to $\mathrm{V}$ through inhalation has also been shown to cause immunological effects, such as significant decreases in lymphocyte stimulation and an increase in the incidence of viral and bacterial respiratory infections in children, a vulnerable population. ${ }^{16}$ Another study examining the health effects of chronically inhaling $\mathrm{V}$ found a significant association between $\mathrm{V}$ and systolic blood pressure and pulse pressure in an elderly population. $^{17}$

Cr appears even more toxic; acute oral exposure has been linked to (1) death, and at lethal doses respiratory effects such as pleural effusions, pulmonary oedema, bronchitis and bronchopneumonia; (2) cardiovascular effects such as cardiopulmonary arrest, cardiac arrest, and a drop in cardiac output, heart rate and blood pressure; (3) gastrointestinal haemorrhage and necrosis, abdominal pain and vomiting; (4) haematological effects such as inhibited coagulation; (5) hepatic effects such as the development of jaundice, fatty degeneration, hepatic necrosis, and increased bilirubin, serum lactic dehydrogenase, alanine and aspartate aminotransferase, and $\gamma$-glutamyl transferase; and (6) renal effects such as renal failure characterised by proteinuria, haematuria and anuria, renal necrosis, necrosis and swelling of renal tubules, oliguria, destruction of the tubular epithelium of the kidneys, and highly elevated serum creatinine and blood urea nitrogen; and (7) metabolic acidosis. ${ }^{8}$ Two studies in particular have shown the effects of chronic oral exposure to $\mathrm{Cr}(\mathrm{VI})$. Both studies are exceptionally relevant to our study and consisted of populations who had $\mathrm{Cr}(\mathrm{VI})$-contaminated drinking water. The first study, from an area near a ferrochromium production plant in the Liaoning Province in China, found an association between contaminated water and gastrointestinal effects such as oral ulcers, diarrhoea, abdominal pain, indigestion and an increased incidence of lung and stomach cancer. ${ }^{8} 19$ The second study, from an area of Greece with elevated $\mathrm{Cr}(\mathrm{VI})$ in the public drinking water, found significantly higher standardised mortality ratios for primary liver, lung, kidney and genitourinary cancer. ${ }^{820}$

Several studies show that the serum concentrations of $\mathrm{V}$ and $\mathrm{Cr}$ are higher in adult haemodialysis patients and patients with CKD; this suggests that they accumulate in the body. ${ }^{51-23}$ Another study confirmed this association by measuring trace elements in the hair of adult haemodialysis patients. ${ }^{6}$ Although data in paediatric patients with CKD are elusive, we hypothesised that similar to dialysis patients, we would find elevated $\mathrm{V}$ and $\mathrm{Cr}$ levels in paediatric patients with CKD who were not receiving dialysis treatments. ${ }^{24}$ We also hypothesised that levels would increase with worsening glomerular filtration rate (GFR).

\section{PATIENTS AND METHODS}

\section{Study design}

The study adhered to the Declaration of Helsinki. The Research Ethics Board of the University of Western Ontario approved the study as part of an intervention study on zinc supplementation in patients with CKD centred at McMaster University (NCT02126293; HC\#172241; REB \#104976). Patients were recruited from April 2014 to April 2016. Given that almost all patients enrolled within the first 3 months had elevated $\mathrm{V}$ and Cr levels, we created this ancillary cross-sectional study to specifically analyse the elevated trace elements in this population. The primary outcome of the original study was patient plasma zinc levels, while the secondary outcomes were the patient plasma trace element levels. 


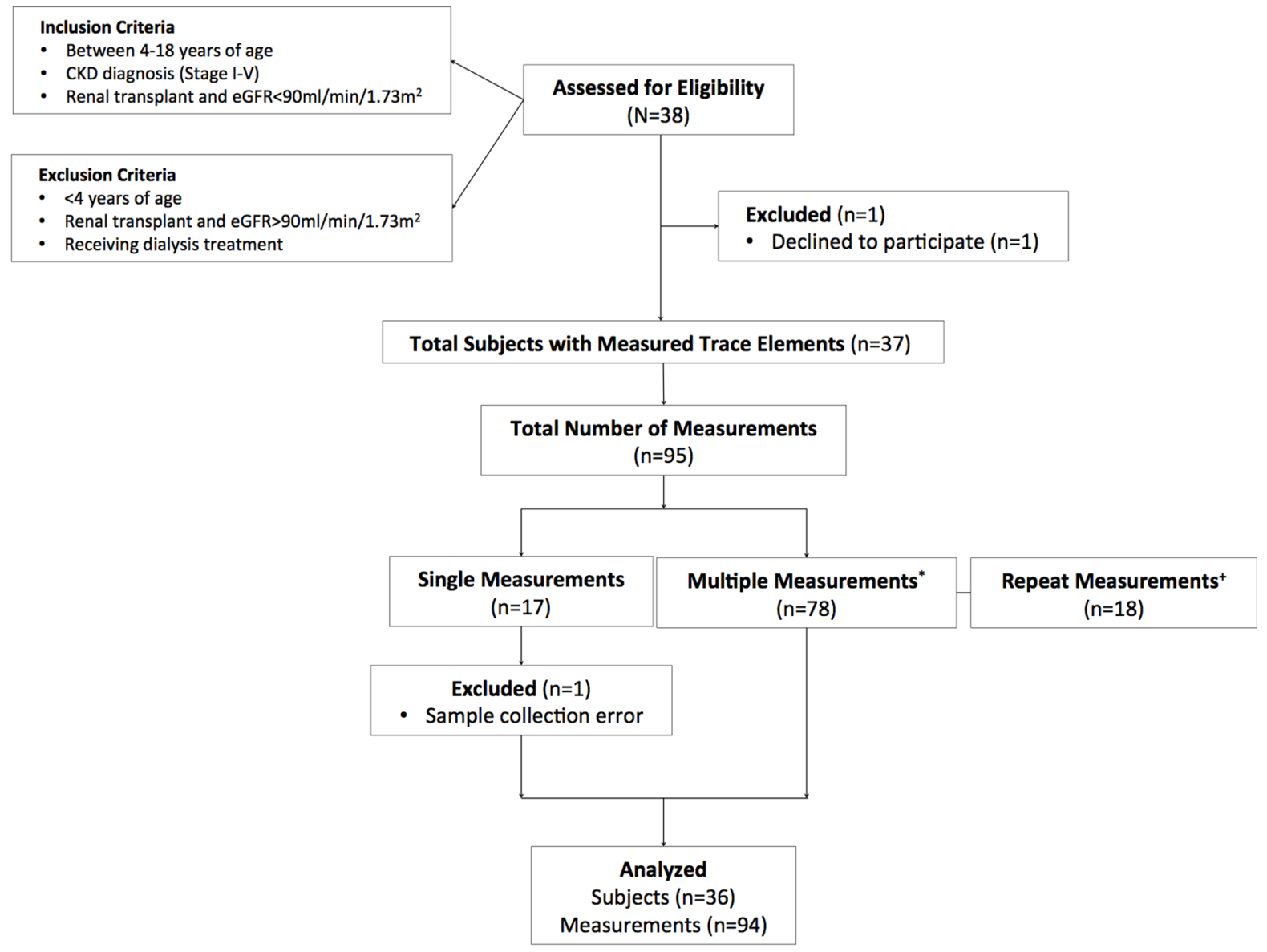

*Multiple measurements: measurements taken over multiple clinic visits

+Repeat measurements: measurements analyzed on the same day and from the same blood sample

Figure 1 Patient flow chart. Of the 38 subjects assessed for eligibility in the study, we included 36 in our analysis. These 36 patients had 94 trace element panel measurements. CKD, chronic kidney disease; eGFR, estimated glomerular filtration rate.

\section{Study population}

Figure 1 shows the inclusion and exclusion criteria. We performed an interim analysis on 36 study patients (16 women, $44 \%$; average age: $11.85 \pm 4.5$ years, age range: $4.42-18.98$ years) with various renal pathologies and diagnosed CKD (as per the Kidney Disease - Improving Global Outcomes (KDIGO) guidelines ${ }^{25}$ ) using the modified Schwartz formula ${ }^{26}$ at the London Health Sciences Centre, a tertiary paediatric nephrology centre. Patients with Stage 1 (estimated glomerular filtration rate (eGFR) $\left.>90 \mathrm{~mL} / \mathrm{min} / 1.73 \mathrm{~m}^{2}\right)$ to Stage $5\left(<15 \mathrm{~mL} / \mathrm{min} / 1.73 \mathrm{~m}^{2}\right)$ CKD were included in the study. Patients receiving dialysis treatments were excluded from the study because the dialysis water could further affect the patients' $\mathrm{V}$ and $\mathrm{Cr}$ levels. Since this was an ancillary study, the study did not specifically select for the stage of CKD, the patient's age or the location of the patient's residence, which could introduce potential bias. Patients also had different numbers of repeated samples, depending on their clinic visits. Patients did not record their fluid or food intake, which could influence the results. To address potential bias due to contaminated drinking water, we matched the postal code of the patient's home with provincial 2014 water quality data.

\section{Experimental methods}

eGFR was calculated using the Filler formula,${ }^{27}$ using the new international reference materials. ${ }^{28}$ Plasma samples were collected in BD K $_{2}$-EDTA Royal Blue Vacutainer tubes (Reference \#368381). V and Cr levels were measured using the high-resolution sector field inductively coupled mass spectrometry (https://ltig.lhsc.on.ca/?action=view rec\&test=Vanadium \% 2C\% 20Plasma;https://ltig.lhsc. on.ca/ ? action=view_rec\&test $=$ Chromium \% 2CPlasma; last accessed 27 June 2016). The total imprecision (CV) of the $\mathrm{V}$ measurements was $10 \%$ at low concentration $(0.100 \mu \mathrm{g} / \mathrm{L}), 4 \%$ at medium concentration $(0.257 \mu \mathrm{g} / \mathrm{L})$ and $8 \%$ at high concentration $(0.356 \mu \mathrm{g} / \mathrm{L})$. For $\mathrm{Cr}$, the total imprecision $(\mathrm{CV})$ was $3 \%(0.82 \mu \mathrm{g} / \mathrm{L}), 4 \%(5.40$ $\mu \mathrm{g} / \mathrm{L})$ and $5 \%(43.60 \mu \mathrm{g} / \mathrm{L})$, respectively. Anthropomorphic data (patient height measured by stadiometer, necessary to calculate the Schwartz eGFR), the first three digits of patients' postal codes and creatinine and cystatin C were collected from our electronic chart programme, PowerChart (Cerner). Data were entered into an Excel spreadsheet (Excel for Mac 2011, V.14.4.4.).

Data analysis was performed using GraphPad Prism 5 for Mac OS X, V.5.0f, and HLM 7.01 (Scientific Software International, Skokie, Illinois, USA). Data were analysed 
for normal distribution using the D'Agostino and Pearson omnibus normality test. As most data were normally distributed, parametric methods were used for all statistical tests, with the exception of the $\mathrm{V}$ and $\mathrm{Cr}$ levels and eGFR, which were expressed as median and interquartile range (25th, 75th percentile). Spearman's rank correlation analysis was used to analyse the correlation analysis of $\mathrm{V}$ levels that were not normally distributed. The Wilcoxon signed-rank test was used to compare the $\mathrm{V}$ and Cr levels with the 97.5th percentile as neither $\mathrm{V}$ nor $\mathrm{Cr}$ levels were normally distributed. A repeated measures analysis was conducted to determine whether the results of repeated measurements (from the same day) affected the original results.

Heat maps depicting $\mathrm{V}$ and $\mathrm{Cr}$ levels in drinking water were generated using data collected by the Government of Ontario for their Provincial (Stream) Water Quality Monitoring Network, which can be found at https://www. ontario.ca/data/ provincial-stream-water-quality-monitoring-network. Only the most recent data were used (2014; https:/ / files.ontario.ca/moe_mapping/downloads/ 2Water/PWQMN_by_year/pwqmn_rawdata_2014.xlsx). The station coordinate data (found at https://files.ontario. ca/moe_mapping/downloads/2Water/PWQMN1.xlsx) was used to determine the longitude and latitude of each testing station in order to generate the map. Since each station had a varying number of results, only the most recent measurement was used, unless that measurement was a negative number, in which case the second most recent measurement was used. Measurements used in the maps were taken between spring and winter of 2014. The V or Cr measurement at each station and the longitude and latitude of each station were then uploaded in two separate files to open-source mapping software created by Pete Warden, which can be found at www.openheatmap.com. Patients' locations in Southern Ontario were mapped using the first three digits of their postal codes (data on file).

\section{RESULTS}

Thirty-six children and adolescents with CKD and at least one set of trace element data were included in the study (figure 1, table 1). The median eGFR was $51 \mathrm{~mL} / \mathrm{min} / 1.73 \mathrm{~m}^{2}(35,75)$. V levels were not normally distributed (D'Agostino and Pearson omnibus test $\mathrm{p}$ value $<0.0001)$. The median $\mathrm{V}$ level was $0.12 \mu \mathrm{g} / \mathrm{L}$ $(0.09,0.18)$ and the maximum $\mathrm{V}$ level was $3.350 \mu \mathrm{g} / \mathrm{L}$. Thirty-two patients had at least one set of $\mathrm{V}$ levels above the published reference interval of $0.088 \mu \mathrm{g} / \mathrm{L}$ (table 2) in either unit, and the results of 75 of the 94 total tests $(80 \%)$ were above the interval. The $\mathrm{V}$ levels were significantly greater than the 97.5 th percentile of the reference interval of $0.088 \mu \mathrm{g} / \mathrm{L}$ (Wilcoxon signed-rank test $\mathrm{p}<0.0001)$. There was a weak negative correlation between the V levels and the eGFR (Spearman $\mathrm{r}=-0.1209$, figure 2). In patients with repeated V levels, there was no statistically significant change between the first and the last measured level (figure 3).

\begin{tabular}{ll}
\hline Table 1 Patient demographics & \\
\hline Variable & $\mathbf{n ~ ( \% )}$ \\
\hline $\begin{array}{l}\text { Gender } \\
\text { Male }\end{array}$ & $22(58 \%)$ \\
\hline Female & $16(42 \%)$ \\
\hline Age group (years) & \\
\hline $4-10$ & $18(47 \%)$ \\
\hline $11-15$ & $9(24 \%)$ \\
\hline $16-18$ & $11(29 \%)$ \\
\hline Primary diagnosis & \\
\hline Hereditary & \\
\hline Renal dysplasia & $11(31 \%)$ \\
\hline Metabolic disorders & $5(14 \%)$ \\
\hline Nephronophthisis & $2(6 \%)$ \\
\hline $\begin{array}{l}\text { Autosomal recessive polycystic kidney } \\
\text { disease }\end{array}$ & $2(6 \%)$ \\
\hline $\begin{array}{l}\text { Autosomal dominant polycystic kidney } \\
\text { disease }\end{array}$ & $1(3 \%)$ \\
\hline $\begin{array}{l}\text { Congenital nephrotic syndrome } \\
\text { Alport syndrome }\end{array}$ & $1(3 \%)$ \\
\hline Acquired & $1(3 \%)$ \\
\hline Reflux nephropathy & \\
\hline Haemolytic uremic syndrome & $4(11 \%)$ \\
\hline $\begin{array}{l}\text { Glomerulonephritis/focal segmental } \\
\text { glomerulosclerosis }\end{array}$ & $3(8 \%)$ \\
\hline Tubulopathy & $3(8 \%)$ \\
\hline Ischaemic renal Injury & $2(6 \%)$ \\
\hline $\begin{array}{l}\text { Yidney transplant } \\
\text { No }\end{array}$ & $1(3 \%)$ \\
\hline & $13(36 \%)$ \\
\hline
\end{tabular}

Cr levels were not normally distributed (D'Agostino and Pearson omnibus test $p$ value $<0.0001$ ). The median Cr level was $0.43 \mu \mathrm{g} / \mathrm{L}(0.36,0.54)$, which was significantly greater than the 97.5 th percentile of the reference interval of $0.31 \mu \mathrm{g} / \mathrm{L}$ (Wilcoxon signed-rank test $\mathrm{p}<0.0001$ ). Thirty-four patients had at least one $\mathrm{Cr}$ level that was above the reference interval for healthy adults (77 of 94 tests $(82 \%))$. There was a very weak non-significant positive

Table 2 Paediatric reference intervals used in our study

\begin{tabular}{lllll}
\multicolumn{2}{l}{ Paediatric reference intervals } \\
\hline \multicolumn{4}{c}{$\mathbf{\mu g} / \mathbf{L}$} & \multicolumn{3}{c}{$\boldsymbol{\mu m o l} / \mathbf{L}$} \\
\hline & Lower & Upper & Lower & Upper \\
Vanadium & 0.032 & 0.088 & 0.6 & 1.7 \\
Chromium & 0.13 & 0.31 & 2.5 & 6 \\
\hline
\end{tabular}

Paediatric-specific vanadium and chromium reference intervals were not available.

Source: http://www.lhsc.on.ca/lab/memos/Reference_Ranges_for_ Trace_Elements_2014_11_03.pdf. 


\section{Vanadium}

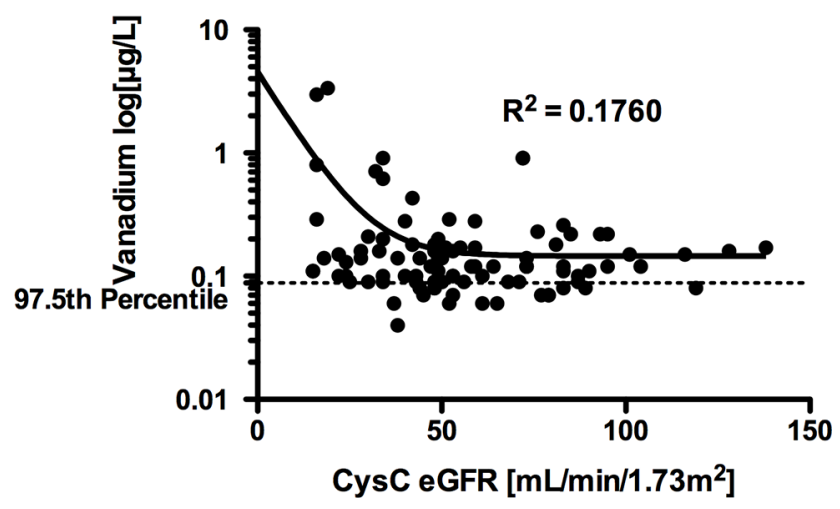

Figure 2 Scatter plot of vanadium levels versus estimated glomerular filtration rate (eGFR). Vanadium levels $(\mu \mathrm{g} / \mathrm{L})$ were not normally distributed. The non-linear regression line (onephase exponential decay) has been included. Glomerular filtration rate was measured in $\mathrm{mL} / \mathrm{min} / 1.73 \mathrm{~m}^{2}$. The formula reads: $\mathrm{Y}=(\mathrm{YO}-\mathrm{Plateau}) \times \exp (-\mathrm{K} \times \mathrm{x})+\mathrm{Plateau}$, where $\mathrm{YO}$ is the value when $x$ is 0 , plateau is $Y$ at a large value, $K$ is the rate constant, and the values were $Y 0=4.555$, Plateau $=0.1457$ and $\mathrm{K}=0.1111$ (GraphPad Prism).

correlation between Cr and eGFR (Spearman $\mathrm{r}=0.09111$, $\mathrm{p}=0.3851$, figure 4 ). The median level did not change from first to last measurement, and the perceived rise in the values was not statistically significant $(\mathrm{p}=0.3381$, Wilcoxon matched-pairs signed-rank test, figure 5). There was a moderate but significant correlation between $\mathrm{V}$ and Cr levels (Spearman $\mathrm{r}=0.5973, \mathrm{p}=<0.0001$ ). Similar results were found with a repeated measures analysis (HLM 7.01; Scientific Software International) that accounted for all measurement points. Neither $\mathrm{V}$ nor $\mathrm{Cr}$ levels were associated with age or season.
The $\mathrm{V}$ levels measured in water ranged from $0.00257 \mu \mathrm{g} / \mathrm{L}$ to $5.87 \mu \mathrm{g} / \mathrm{L}$, and the measured Cr levels in water ranged from $0.0099 \mu \mathrm{g} / \mathrm{L}$ to $4.32 \mu \mathrm{g} / \mathrm{L}$. The mapped $\mathrm{V}$ data show higher concentrations grouped along the Detroit and St Clair river, as well as the shores around Lake Erie and Lake Huron (figure 6). The mapped $\mathrm{Cr}$ levels show the same general distribution pattern but with slightly larger values overall (figure 7).

Comparing the two maps with a map of the patients' locations from the study, we found that although some groupings of patients corresponded to the areas of high $\mathrm{V}$ and $\mathrm{Cr}$ (such as Windsor, St Thomas, Hanover and Owen Sound; $n=8$ ), others were located in areas of low concentrations.

\section{DISCUSSION}

Our study demonstrates a high prevalence of elevated $\mathrm{V}$ and $\mathrm{Cr}$ levels in paediatric patients with CKD. With $\mathrm{V}$, this trend is strongest in patients with an eGFR of less than $30 \mathrm{~mL} / \mathrm{min} / 1.73 \mathrm{~m}^{2}$. In 28 of the 36 patients, $\mathrm{V}$ and $\mathrm{Cr}$ exposure in drinking water did not seem to be the major contributing factor.

Homeostasis of both trace elements depends on uptake and elimination. Uptake occurs through different types of environmental exposures, namely through the air, water, food and soil. More than $70 \%$ of $\mathrm{Cr}$ in the environment comes from anthropogenic sources, such as non-ferrous base metal smelters, refineries, leather tanning industries, urban storm water run-off, effluent streams from pulp and paper mills, and discharges from thermal generating stations. ${ }^{29}$ In Canada, it is largely released into the atmosphere through different means of pollution, namely industrial processes $(1 / 3)$, stationary fuel consumption

\section{Longitudinal Plasma Vanadium}

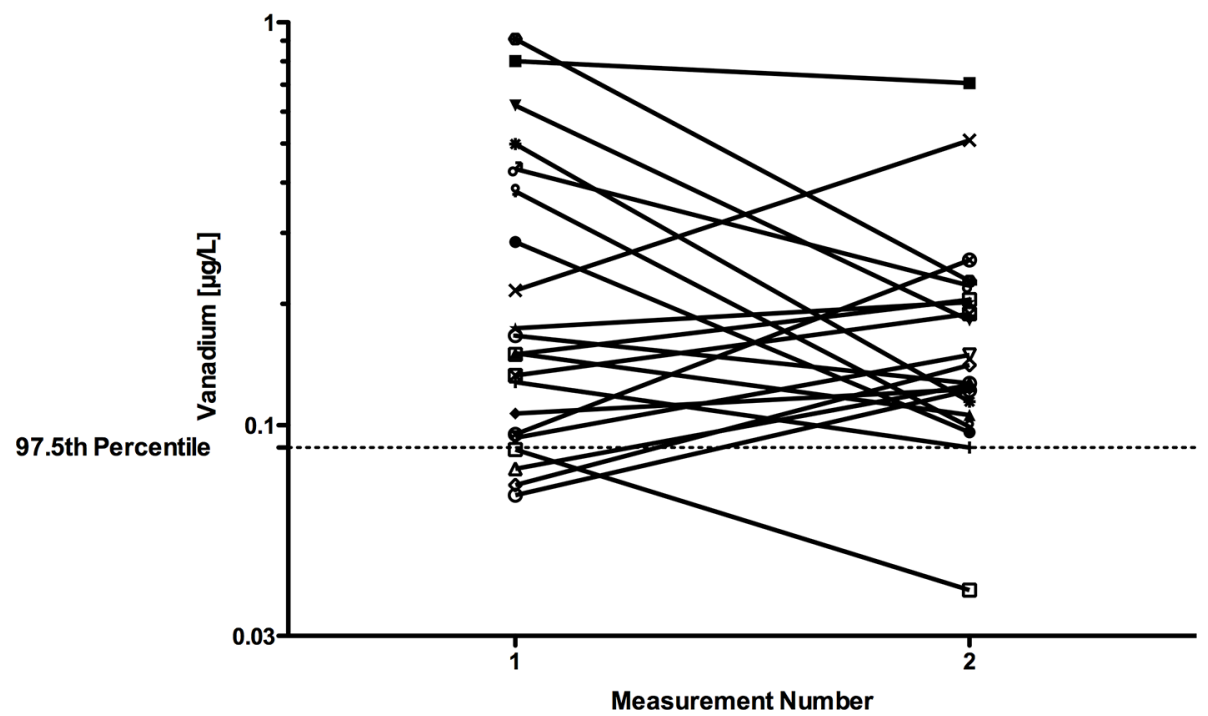

Figure 3 Repeated measures plot of first and last vanadium level in those patients who had repeated levels. Vanadium levels $(\mu \mathrm{g} / \mathrm{L})$ were not normally distributed. While the median vanadium level lowered from 0.1510 to $0.1410 \mu \mathrm{g} / \mathrm{L}$, and many patients demonstrated an increase of their vanadium level with repeated measures, this did not reach statistical significance $(p=0.4140$, Wilcoxon matched-pairs signed-rank test). 


\section{Chromium}

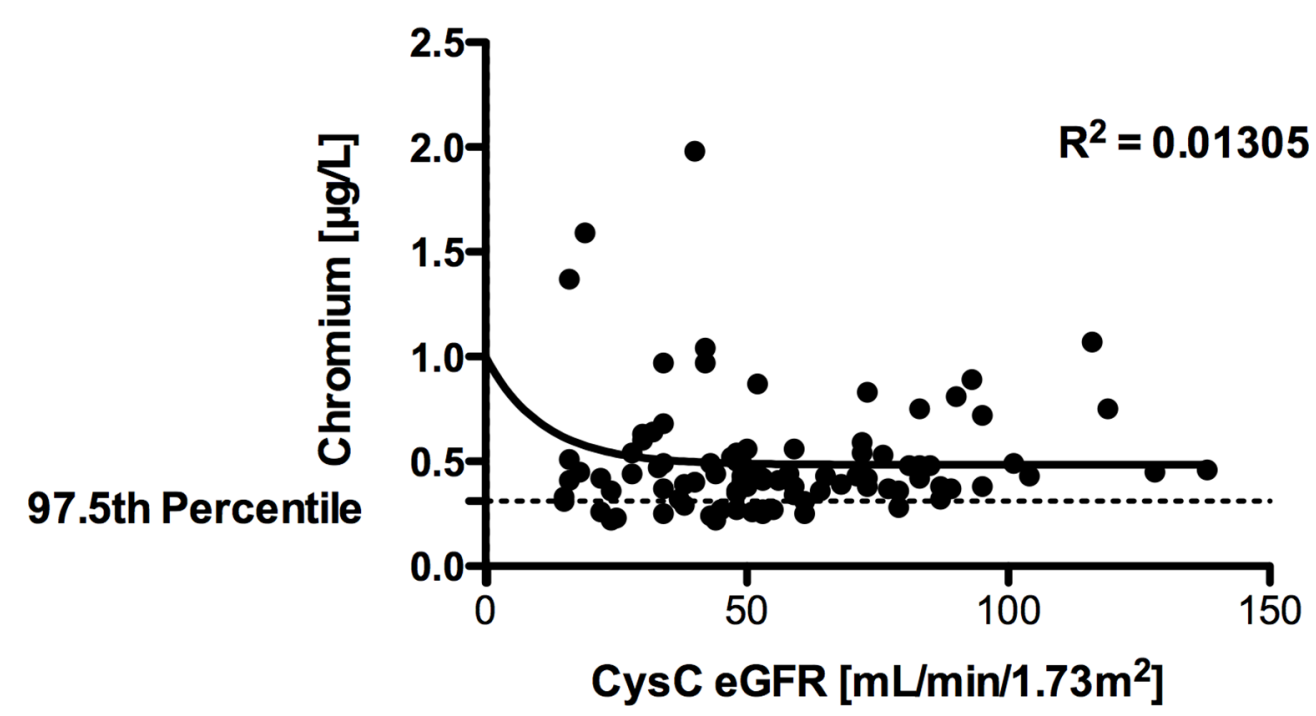

Figure 4 Scatter plot of chromium levels versus estimated glomerular filtration rate (eGFR). Chromium levels $(\mu \mathrm{g} / \mathrm{L})$ were not normally distributed. The non-linear regression line (one-phase exponential decay) has been included. Glomerular filtration rate was measured in $\mathrm{mL} / \mathrm{min} / 1.73 \mathrm{~m}^{2}$. The formula reads: $\mathrm{Y}=(\mathrm{YO}-\mathrm{Plateau}) \times \exp (-\mathrm{K} \times \mathrm{x})+\mathrm{Plateau}$, where $\mathrm{Y} 0$ is the value when $\mathrm{x}$ is 0 , Plateau is $\mathrm{Y}$ at a large value, $\mathrm{K}$ is the rate constant, and the values were $\mathrm{Y} 0=1.641$, Plateau $=0.4841 \mathrm{and} \mathrm{K}=0.09060(\mathrm{GraphPad}$ Prism).

$(1 / 2)$ and transportation $(3 / 20) . .^{30}$ Ground water and other fresh water contain $\mathrm{V}$ (in the form of $\mathrm{H}_{2} \mathrm{VO}_{4}^{-}$) at an approximate concentration of $1.17 \mu \mathrm{g} / \mathrm{L}$, fats, fruits and vegetables at $1-5 \mu \mathrm{g} / \mathrm{kg}$, and meat, seafood, whole grains and dairy products at $5-30 \mu \mathrm{g} / \mathrm{kg} .{ }^{31}$ The daily intake via food is usually between 10 and $200 \mu \mathrm{g} .{ }^{32} \mathrm{Cr}$ (III), the less toxic isoform of $\mathrm{Cr}$, is also naturally found in many foods. ${ }^{8}$ Both hexavalent and trivalent $\mathrm{Cr}$ are found in water. ${ }^{29}$

Although previous studies have shown elevated $\mathrm{V}$ and Cr levels in adult dialysis patients, ${ }^{22}$ we are unaware of any published work showing high $\mathrm{V}$ and $\mathrm{Cr}$ levels in paediatric patients with CKD other than in abstract form. ${ }^{33}$ Since

\section{Longitudinal Plasma Chromium}

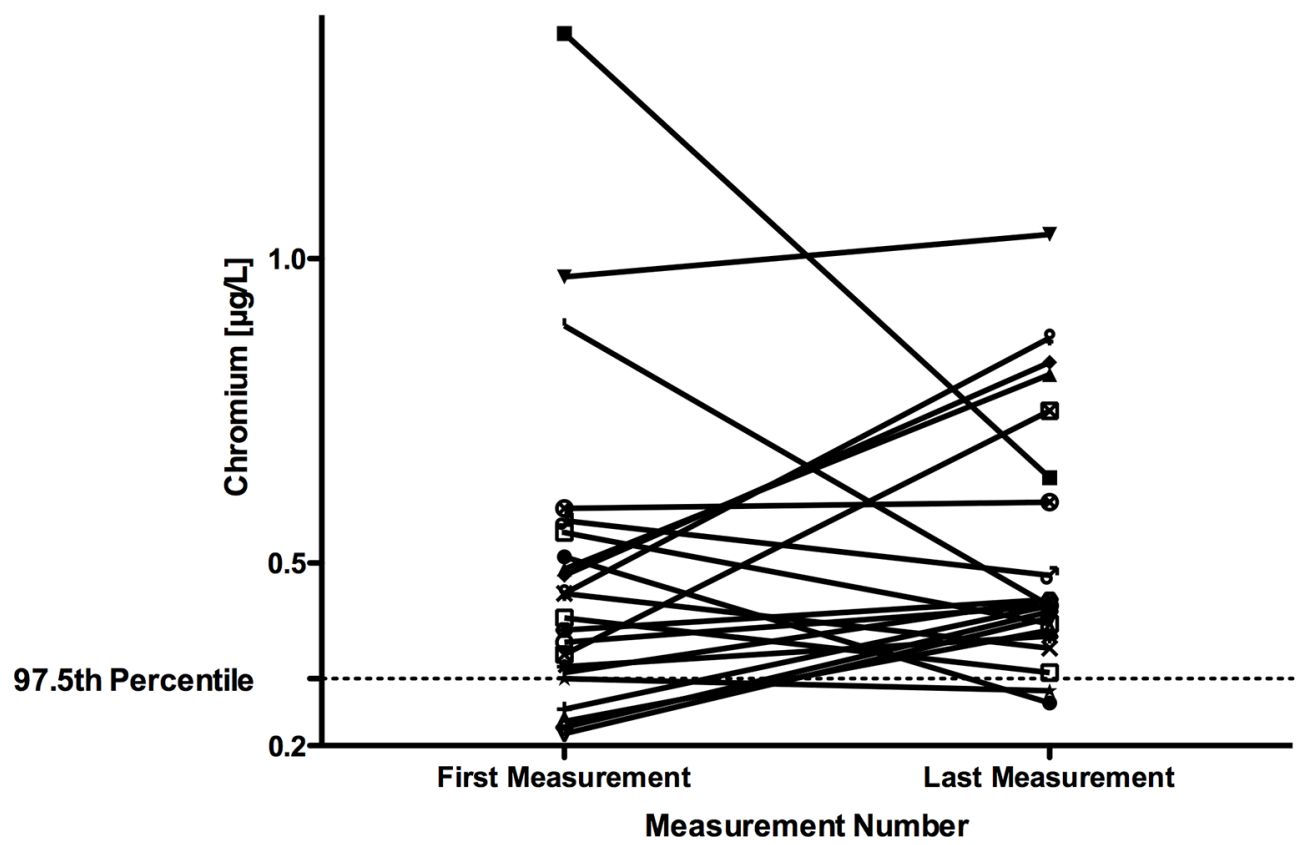

Figure 5 Repeated measures plot of first and last chromium level in those patients who had repeated levels. Chromium levels $(\mu \mathrm{g} / \mathrm{L})$ were not normally distributed. The median chromium level did not change from $0.44 \mu \mathrm{g} / \mathrm{L}$ and the rise in the values was not statistically significant ( $\mathrm{p}=0.3381$, Wilcoxon matched-pairs signed-rank test). 


\section{Heat Map Vanadium}

OPENHEATMAP

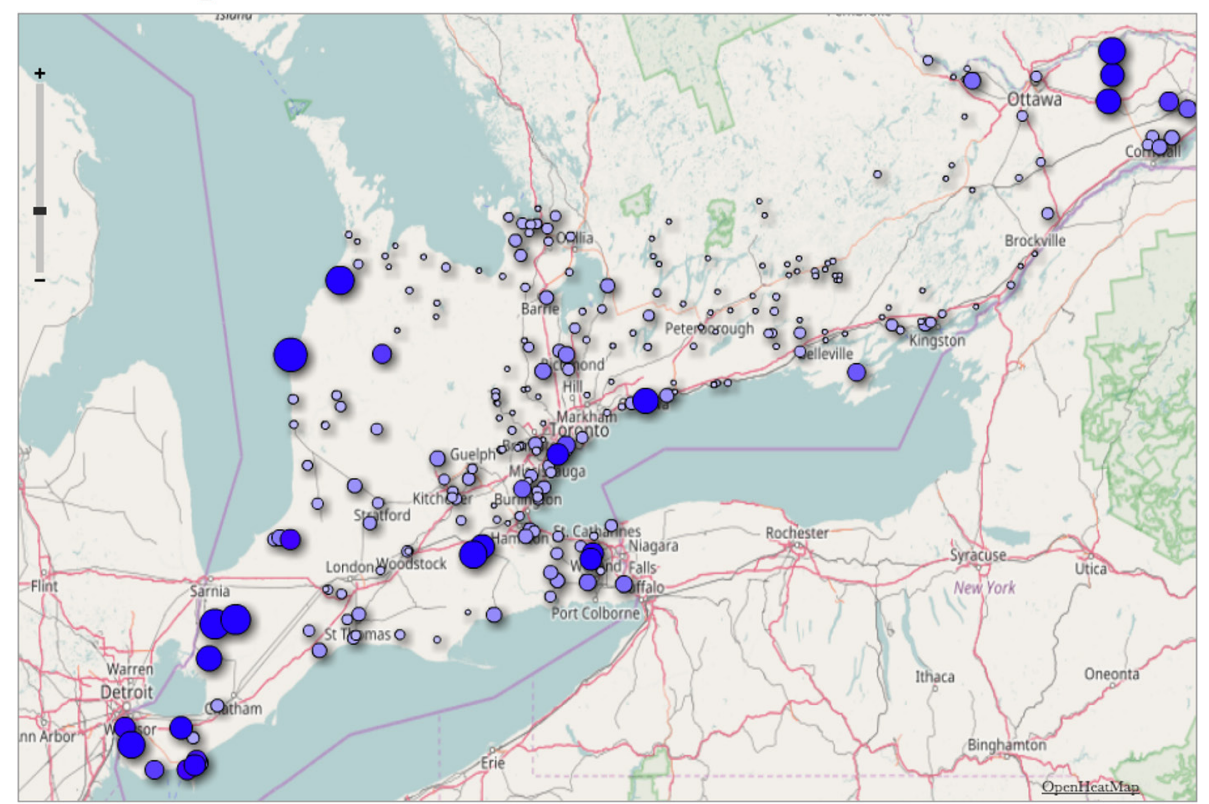

Value $\quad 0.119 \quad 1.36 \quad 2.60$

Figure 6 Heat map showing the concentration of vanadium in 2014 in various streams around Southwestern Ontario. Map created using 2014 data from the Provincial (Stream) Water Quality Monitoring Network at https://www.ontario.ca/data/ provincial-stream-water-quality-monitoring-network in open-source software found at www.openheatmap.com.

patients with CKD are usually polyuric and develop polydipsia, their exposure to $\mathrm{V}$ in drinking water is several-fold greater than the general population. Combined with the fact that $\mathrm{V}$ is mainly eliminated through the kidneys, ${ }^{13}$ this vulnerable population's environmental exposure to toxic trace elements may pose a danger, especially if they have polyuria and polydipsia and drink contaminated water. We suspect that in addition to our patients' low V

\section{Heat Map Chromium}

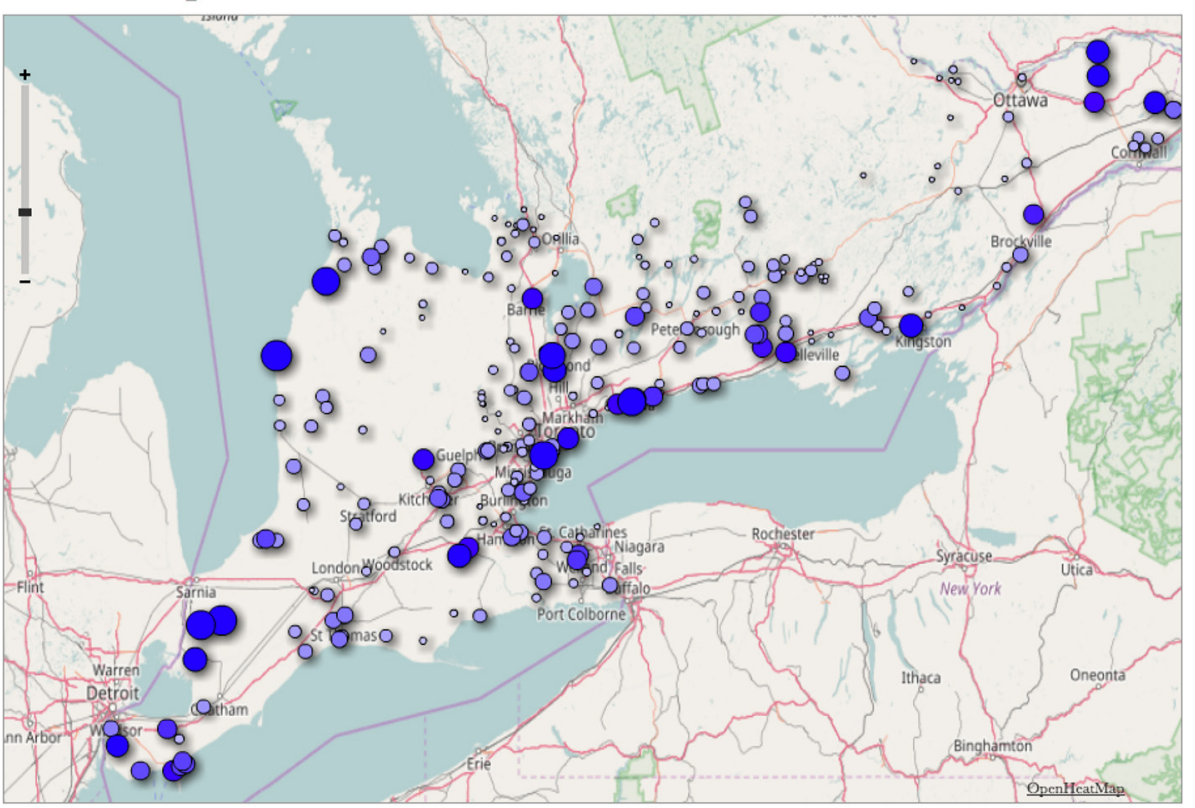

\begin{tabular}{l|l|l|l|} 
Chromium & 0.117 & 1.21 & 2.31
\end{tabular}

Figure 7 Heat map showing the concentration of chromium in 2014 in various streams around Southwestern Ontario. Map created using 2014 data from the Provincial (Stream) Water Quality Monitoring Network at https://www.ontario.ca/data/ provincial-stream-water-quality-monitoring-network in open-source software found at www.openheatmap.com. 
and $\mathrm{Cr}$ clearance, their significantly greater exposure to $\mathrm{V}$ and $\mathrm{Cr}$ in drinking water is the reason for their high levels of both elements. Since some groupings of patients corresponded to the areas of high $\mathrm{V}$ and $\mathrm{Cr}$ and others did not, this leads us to believe that our findings are the result of both environmental factors and impaired kidney function.

There are few guidelines for maximum $\mathrm{V}$ concentrations in the environment, and those that exist either cover a wide range from different sources, are outdated or were determined using extremely limited and unacceptable methodologies. ${ }^{34}$ The Office of Environmental Health Hazard Assessment in California released a statement in August of 2000 in response to the Department of Health Service's proposed level not exceeding $50 \mu \mathrm{g} / \mathrm{L}$, recommending a lower level of $15 \mu \mathrm{g} / \mathrm{L} .^{35}$ Meanwhile, Environment Canada released the Federal Environmental Quality Guidelines for V in May of 2016, listing the predicted no-effect concentration for marine water at $5 \mu \mathrm{g} / \mathrm{L}$ and for freshwater at $120 \mu \mathrm{g} / \mathrm{L}$. The Canadian federal government does not include $\mathrm{V}$ in their most recent Guidelines for Canadian Drinking Water Quality (2014) ${ }^{36}$ nor is it included in the water quality guidelines used by Ontario. ${ }^{37}$ Other Canadian water quality guidelines list standards ranging from 3.9 to $250 \mu \mathrm{g} / \mathrm{L} .{ }^{389}$ The standard for $\mathrm{Cr}$ in Ontario drinking water is $50 \mu \mathrm{g} / \mathrm{L}$. The Centers for Disease Control has established some minimal risk levels for humans, defined as an estimate of daily human exposure to $\mathrm{V}$ and $\mathrm{Cr}$ that is likely to be without an appreciable risk of adverse effects over a specified duration of exposure. ${ }^{7}$ These limits are as follows: oral acute (none), intermediate duration $(10 \mu \mathrm{g} / \mathrm{kg} /$ day for $\mathrm{V}$ and $0.5 \mu \mathrm{g} / \mathrm{kg} /$ day for $\mathrm{Cr}$ ) and chronic duration (none for $\mathrm{V}$ and $0.9 \mu \mathrm{g}$ / $\mathrm{kg}$ /day for $\mathrm{Cr}$ ).

The average concentration of $\mathrm{Cr}$ in uncontaminated surface and marine water is generally below $1.0 \mu \mathrm{g} / \mathrm{L},{ }^{30}$ but in Ontario these numbers can be much greater at sites most severely affected by pollution. This includes the St Marys River system with concentrations of $31000 \mu \mathrm{g} / \mathrm{g}$ dry weight $(\mathrm{dw})$ in Tannery Bay and concentrations exceeding $5120 \mu \mathrm{g} / \mathrm{g}(\mathrm{dw})$ in the Welland River downstream from a steel manufacturing plant compared with $10 \mu \mathrm{g} / \mathrm{g}(\mathrm{dw})$ upstream. ${ }^{30} \mathrm{Up}$ to $1920 \mu \mathrm{g} / \mathrm{g}(\mathrm{dw})$ has been found in Detroit River sediments and $564 \mu \mathrm{g} / \mathrm{g}(\mathrm{dw})$ in Hamilton Harbour sediments. ${ }^{6}$ Elevated concentrations of twofold to fourfold above local background levels have also been reported in sediments from Lake Simcoe, the Detroit River, Lake Ontario off the Niagara River and the St Lawrence River. ${ }^{32}$ Our catchment area overlaps with several of these areas.

Twenty-eight of our patients were not from the highly polluted areas. However, some of the highest $\mathrm{V}$ and $\mathrm{Cr}$ levels were observed in patients with a low GFR, despite living in areas with low $\mathrm{V}$ and $\mathrm{Cr}$ exposure. We believe that the high water intake with CKD and the low GFR are two additional factors that result in the high prevalence of elevated $\mathrm{V}$ and $\mathrm{Cr}$ in these patients.
Clearly, the scientific evidence indicating both the safe levels and the resultant toxicity of $\mathrm{V}$ in our air, water and food is lacking, of poor quality and conflicting, especially considering how little, if any, of this research has been done on (1) vulnerable populations such as children and (2) children with impaired renal or hepatic function. The guidelines for $\mathrm{Cr}$ are slightly clearer considering its increased toxicity, but there are still little data on chronic safe levels and toxicity. Since high V and Cr levels are seen in such a large proportion of our study population, and since the environmental levels of $\mathrm{V}$ and $\mathrm{Cr}$ and the resultant health implications are mostly unknown, the question becomes: how can we limit the exposure of children with poor renal function to these potentially toxic trace elements?

Several studies have shown the potential of chelating agents such as iron in reducing $\mathrm{V}$ body burden and toxicity. ${ }^{7}$ The safety and efficacy of this strategy have not been established in children. Therefore, preventing high exposure may be the only feasible strategy, but using bottled water with low trace element levels may be very costly.

Astrength of our study is its cross-sectional design in combination with longitudinal data and a reasonable number of patients for a paediatric pilot study. Another strength is the high precision of the instruments used to measure the trace elements. There are still several limitations. More subjects would have lead to more precise data, and our patient cohort has a bias towards milder CKD stages, which could have potentially minimised the trace element levels seen in this population. Additionally, although the reference intervals that we used were specific to our catchment area and to the equipment used to measure plasma trace elements at our site, they are based on a cohort of adults and have not been published. We did not assess whether the patients drink municipal water, well water or bottled water (with presumably lower concentrations), nor did we assess their total fluid intake. We also did not control for food intake. Certain foods such as fish, shellfish ${ }^{40}$ and grains and cereals $^{41}$ may contain dangerous $\mathrm{V}$ concentrations. These potential confounders could have minimised the environmental impact of the high levels in this population. Finally, detailed studies on the age dependency of paediatric $\mathrm{V}$ and $\mathrm{Cr}$ concentrations are elusive. Additionally, the tubulotoxicity of $\mathrm{Cr}$, in particular, may influence the progression of CKD. Although we did not examine the tubulotoxicity found in our patient cohort, there is often mixed tubular and glomerular proteinuria in patients with CKD and proximal tubular dysfunction in CKD. ${ }^{42}$ Some recent research in animal models has suggested that selenium supplementation could reverse some of the tubular damage. ${ }^{43}$ Of course, haematopoiesis is impaired in the advanced stages of CKD and nephrotoxicity should be avoided.

Despite these limitations, our data robustly demonstrate a high prevalence of elevated $\mathrm{V}$ and $\mathrm{Cr}$ levels in children with CKD. There was a trend towards higher V levels with worsening kidney function. Our data would favour monitoring $\mathrm{V}$ and $\mathrm{Cr}$ in paediatric patients with 
CKD, especially in areas with high exposures or in very polyuric patients.

Acknowledgements The authors would like to thank Mrs Maria McCann and Mr Colin Bradley for their outstanding commitment to the highest level of performance with regard to measuring the trace elements on MS/MS at the Trace Element Laboratory at the London Health Sciences Centre. We would also like to thank Michael Miller, PhD, for helping our team by analysing all of the data using a repeated measures analysis.

Contributors GF and VB articulated the conceptual framework for both the original RCT study and this ancillary study. GF developed the analytical approach, and GF and MK analysed the data. GF, MK and HKS drafted and edited the manuscript. VB, SHSH and LY contributed to the interpretation of data, added intellectual content during manuscript preparation and provided valuable feedback on various aspects of the manuscript. All authors read and approved the final manuscript.

Funding This study was supported through funding from Hamilton Health Sciences in the form of a New Investigator Fund Award (NIF13312) awarded to Dr Vladimir Belostotsky.

Competing interests None declared.

Ethics approval Western University REB.

Provenance and peer review Not commissioned; externally peer reviewed. Data sharing statement Data are available on request.

Open Access This is an Open Access article distributed in accordance with the Creative Commons Attribution Non Commercial (CC BY-NC 4.0) license, which permits others to distribute, remix, adapt, build upon this work non-commercially, and license their derivative works on different terms, provided the original work is properly cited and the use is non-commercial. See: http://creativecommons.org/ licenses/by-nc/4.0/

C Article author(s) (or their employer(s) unless otherwise stated in the text of the article) 2017. All rights reserved. No commercial use is permitted unless otherwise expressly granted.

\section{REFERENCES}

1. Heinemann G, Fichtl B, Vogt W. Pharmacokinetics of vanadium in humans after intravenous administration of a vanadium containing albumin solution. Br J Clin Pharmacol 2003;55:241-5.

2. WHO. Chromium in Drinking-water Geneva. 2003 http://www. who.int/water_sanitation_health/dwq/chemicals/chromium.pdf (accessed 13 Jul 2016)

3. Mukherjee B, Patra B, Mahapatra S, et al. Vanadium--an element of atypical biological significance. Toxicol Lett 2004;150:135-43.

4. Gruzewska K, Michno A, Pawelczyk T, et al. Essentiality and toxicity of vanadium supplements in health and pathology. J Physiol Pharmacol 2014;65:603-11.

5. Hosokawa S, Yamaguchi O, Yoshida O. Vanadium transfer during haemodialysis. Int Urol Nephrol 1991;23:407-9.

6. Ochi A, Ishimura E, Tsujimoto Y, et al. Trace elements in the hair of hemodialysis patients. Biol Trace Elem Res 2011;143:825-34.

7. Services USDoHaH. Toxicological Profile for Vanadium. United States: United States Government, 2012. http://www.atsdr.cdc.gov/ ToxProfiles/tp58.pdf. (accessed 11 Jul 2016).

8. Services USDoHaH. Toxicological Profile for Chromium. United States: United States Government, 2012. http://www.atsdr.cdc.gov/ ToxProfiles/tp7.pdf. (accessed 11 Jul 2016).

9. Lagerkvist B, Nordberg GF, Vouk VV. Handbook on the toxicology of metals. 2 Ed. Amsterdam: Elsevier Science Publishers, 1986.

10. Barceloux DG. Vanadium. J Toxicol Clin Toxicol 1999;37:265-78.

11. Cite? T-ht. ToxGuide for Vanadium V. In: Services UDoHaH, ed 2012.

12. Rehder D. Biological and medicinal aspects of vanadium. Inorg Chem Commun 2003;6:604-17.

13. WHO. Trace elements in human nutrition and health. Geneva: WHO, 1996.

14. Crebelli R, Leopardi P. Long-term risks of metal contaminants in drinking water: a critical appraisal of guideline values for arsenic and vanadium. Ann Ist Super Sanita 2012;48:354-61.

15. Europe WHOROf. Chapter 6.12: Vanadium. Chromium in Drinkingwater, 2000. http://www.who.int/water_sanitation_health/dwq/ chemicals/chromium.pdf. (accessed 21 Jul 2016).
16. Lener JKJ, Kodl M , et al. Health effects of environmental exposure to vanadium. Vanadium in the environment Part 2: Health Effects. New York, NY: John Wiley \& Sons, 1998:1-19.

17. Jacobs L, Buczynska A, Walgraeve C, et al. Acute changes in pulse pressure in relation to constituents of particulate air pollution in elderly persons. Environ Res 2012;117:60-7.

18. Barth A, Schaffer AW, Konnaris C, et al. Neurobehavioral effects of vanadium. J Toxicol Environ Health A 2002;65:677-83.

19. Zhang JD, Li XL, XI L. [Chromium pollution of soil and water in Jinzhou]. Zhonghua Yu Fang Yi Xue Za Zhi 1987;21:262-4.

20. Linos A, Petralias A, Christophi CA, et al. Oral ingestion of hexavalent chromium through drinking water and Cancer mortality in an industrial area of Greece--an ecological study. Environ Health 2011;10:50.

21. Bello-Reuss EN, Grady TP, Mazumdar DC. Serum vanadium levels in chronic renal disease. Ann Intern Med 1979;91:743.

22. Tonelli M, Wiebe N, Hemmelgarn B, et al. Trace elements in hemodialysis patients: a systematic review and meta-analysis. BMC Med 2009;7:25.

23. Shaban $\mathrm{H}$, Ubaid-Ullah $\mathrm{M}$, Berns JS. Measuring vitamin, mineral, and trace element levels in Dialysis patients. Semin Dial 2014;27:582-6.

24. Filler G, Felder S. Trace elements in dialysis. Pediatr Nephrol 2014;29:1329-35.

25. Kidney disease: improving global outcomes CKDMBDWG. KDIGO clinical practice guideline for the diagnosis, evaluation, prevention, and treatment of chronic kidney Disease-Mineral and bone disorder (CKD-MBD). Kidney Int Supp/ 2009;113:S1-130.

26. Schwartz GJ, Muñoz A, Schneider MF, et al. New equations to estimate GFR in children with CKD. J Am Soc Nephrol 2009;20:629-37.

27. Filler G, Lepage N. Should the Schwartz formula for estimation of GFR be replaced by cystatin C formula? Pediatr Nephrol 2003;18:981-5.

28. Grubb A, Blirup-Jensen S, Lindström V, et al. First certified reference material for cystatin $\mathrm{C}$ in human serum ERM-DA471/IFCC. Clin Chem Lab Med 2010;48:1619-21.

29. Agency EP. Chromium in Drinking Water, 2015. https://www.epa.gov/ dwstandardsregulations/chromium-drinking-water. (accessed $15 \mathrm{Jul}$ 2016)

30. Canada H. Chromium and its compounds: government of Canada; 2007 [updated 2007 (accessed 12 Oct 2016)

31. Rehder D. The future of/for vanadium. Dalton Trans 2013;42:11749-61.

32. Scior T, Guevara-García A, Bernard P, et al. Are vanadium compounds drugable? structures and effects of antidiabetic vanadium compounds: a critical review. Mini Rev Med Chem 2005;5:995-1008.

33. Sidhu H, Filler G, Belostotsky V, et al. High prevalence of elevated vanadium levels in CKD patients. Pediatric nephrology 2016;31:1907-8.

34. BHPBilliton. EKATI Diamond Mine - Site-Specific Water Quality Objective for Vanadium. 2012. http://www.mvlwb.ca/Boards/WLWB/ Registry/2012/W2012L2-0001/W2012L2-0001 - Ekati - Report SSWQO - Vanadium -_12.pdf (accessed 11 Jul 2016).

35. Assessment OoEHH. Proposed Notification Level for Vanadium. http://oehha.ca.gov/water/notification-level/proposed-notificationlevel-vanadium (accessed 11 Jul 2016).

36. Water F-P-TCoD. Guidelines for Canadian Drinking Water Quality. 2014. http://www.hc-sc.gc.ca/ewh-semt/alt_formats/pdf/pubs/watereau/sum_guide-res_recom/sum_guide-res_recom_2014-10_eng.pdf (accessed 11 Jul 2016).

37. Canada GoC-EaCC. Water Quality Guidelines Used by Ontario. 2016. https://www.ec.gc.ca/indicateurs-indicators/default.asp?lang= en\&n=93177156-1 (accessed 11 Jul 2016)

38. Environment OMot. Soil, Ground Water and Sediment Standards for Use under Part XV. 1 of the Environmental Protection Act Canada, 2011. https://dr6j45jk9xcmk.cloudfront.net/documents/998/ 3-6-3-sediment-standards-en.pdf. (accessed 11 Jul 2016).

39. TCCoMot E. Vanadium Canada1997. http://cegg-rcqe.ccme.ca/ download/en/286 (accessed 11 Jul 2016).

40. Copat C, Arena G, Fiore M, et al. Heavy metals concentrations in fish and shellfish from eastern mediterranean sea: consumption advisories. Food Chem Toxicol 2013;53:33-7.

41. Imtiaz M, Rizwan MS, Xiong S, et al. Vanadium, recent advancements and research prospects: a review. Environ Int 2015;80:79-88

42. Waikar SS, Sabbisetti V, Ärnlöv J, et al. Relationship of proximal tubular injury to chronic kidney disease as assessed by urinary kidney injury molecule-1 in five cohort studies. Nephrol Dial Transplant 2016;31:1460-70. 
43. Soudani N, Sefi M, Ben Amara I, et al. Protective effects of Selenium

Environ Saf 2010;73:671-8.

$(\mathrm{Se})$ on Chromium (VI) induced nephrotoxicity in adult rats. Ecotoxicol 